\title{
Cladosporium macrocarpum brain abscess after endoscopic ultrasound-guided celiac plexus block
}

A 45-year-old man presented with a 24hour history of holocranial headache and right-side deviation of the oral commissure. He denied fever and other neurological symptoms. He had undergone endoscopic ultrasound (EUS)-guided celiac plexus neurolysis (CPN) 3 weeks before for the management of refractary epigastric pain caused by alcoholic chronic pancreatitis.

On physical examination, cachexia (due to exocrine pancreatic insufficiency) was evident (body mass index of $16 \mathrm{~kg} / \mathrm{m}^{2}$ ). Temperature was $36.7^{\circ} \mathrm{C}$. Neurologic examination revealed only a right central facial palsy. Blood count and chemistry were normal except for: platelets. $53000 / \mu \mathrm{L}$;

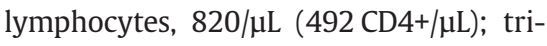
glyceride level, $68 \mathrm{mg} / \mathrm{dL}$; albumin level, $68 \mathrm{mg} / \mathrm{dL}$; and gamma-glutamyl transferase level, $339 \mathrm{UI} / \mathrm{dL}$.

Neuroimaging suggested the diagnosis of a brain abscess ( $\bullet$ Fig. 1 and 2 ).

Lumbar puncture was normal. Chest and abdominal computed tomography scan only revealed calcifications at the pancreatic area with homogeneous splenomegaly and portal thrombosis. A transthoracic echocardiography with contrast injection did not identify an intracardiac right-toleft shunt. HIV and Toxoplasma gondii serologies were negative. Blood cultures were sterile and tuberculin test was negative.

Treatment with meropenem ( $6 \mathrm{~g} /$ day) and ampicillin ( $2 \mathrm{~g} / 4$ hours) was started. The patient underwent a stereotactic brain biopsy with evacuation of a purulent abscess. The Gram stain of the abscess showed Gram-positive bacilli. Direct vision with potassium hydroxide showed pigmented fungal structures suggestive of dematiaceae fungi infection. Treatment with voriconazole was initiated $(400 \mathrm{mg} /$ day i.v.). The darkly pigmented mold isolated was identified as Cladosporium macrocarpum, and the bacteria as Streptococcus constellatus. The patient completed 30 days more of treatment with cefotaxime ( $2 \mathrm{~g} / 6$ hours i.v.) and metronidazole ( $1.5 \mathrm{~g} /$ day i.v.). He was discharged from hospital on oral amoxicillin-clavulanic acid ( $4 \mathrm{~g} /$ day) and oral voriconazole (400 mg/day). Cranial scans showed a progressive reduction of the lesions.

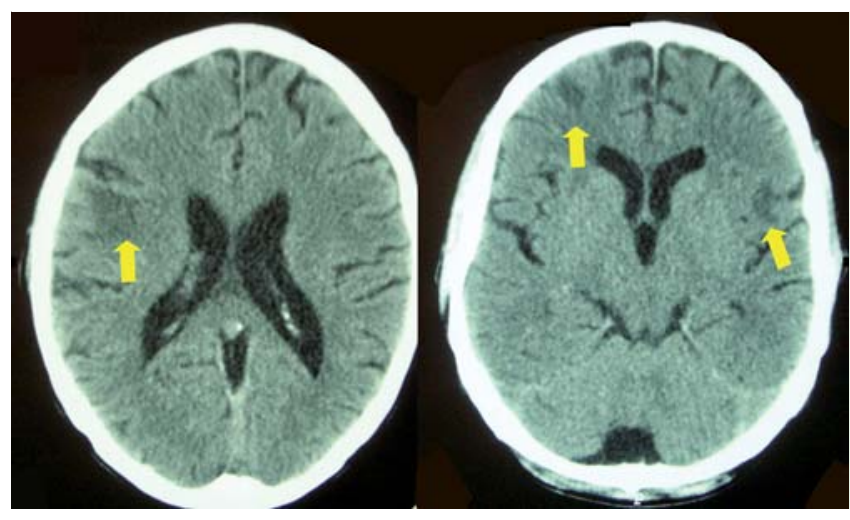

Fig. 1 A computed tomography scan of the brain demonstrated three cortical-subcortical lesions (arrows), two of them involving the right frontal lobe and another one measuring $1.4 \mathrm{~cm}$ in the left Silvio cisure, surrounded by edema.

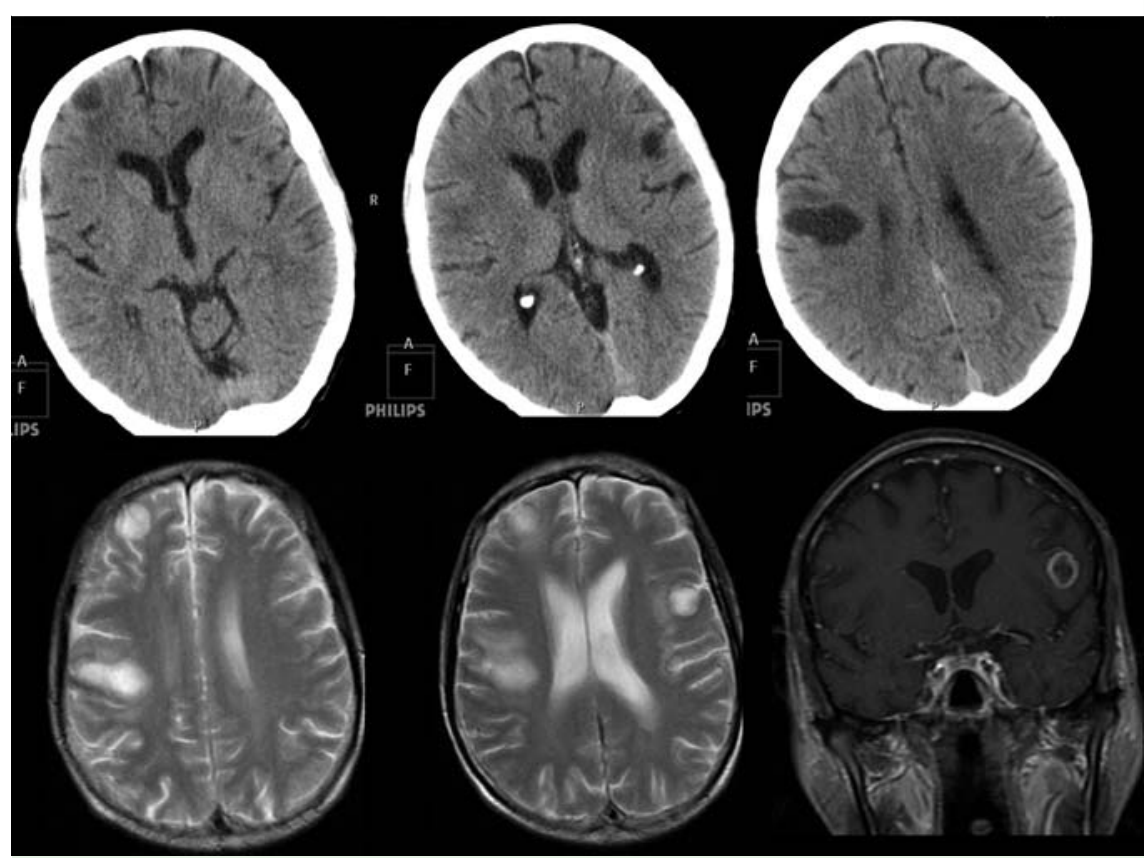

Fig. 2 On gadolinium-enhanced T1-weighted imaging, the lesions showed intense ring enhancing. On diffusion-weighted imaging the lesion had hyperintensity, and apparent diffusion coefficient maps showed hypointensity, consistent with restricted diffusion. These changes strongly suggested the diagnosis of a brain abscess.

Brain abscesses are exceptional after endoscopic procedures $[1,2]$. This is, to the best of our knowledge, the first case report of a brain abscess after EUS-guided CPN. In our case, the microorganisms could have reached the brain through blood vessels by directly spreading from the upper gastrointestinal tract following $\mathrm{CPN}$. The hematogenous spread, and the resulting brain abscess development was aided by the cellular immunodeficiency (characterized by lymphocytopenia).

Dematiaceous fungi comprise a heterogeneous group of fungi that contain melanin in their cell walls. The most severe forms of phaeohyphomycosis are infections of the central nervous system $[3,4]$. Brain abscess is a rare and frequently fatal manifestation of phaeohyphomycosis, often in immunocompetent individuals. The most common species responsible is Cladophialophora bantiana [3]. The treatment requires both complete excision of the brain abscess and antifungal therapy (itraconazole, voriconazole or amphotericin B) [5]. Therapy should not be stopped until complete radiographic resolution occurs [5]. The mortality is about $100 \%$ without treatment, and $65 \%$ for those who are treated with surgery and chemotherapy $[3,4]$. 


\section{Endoscopy_UCTN_Code_CPL_1AL_2AG}

\section{Competing interests: None}

\section{A. Lalueza ${ }^{1}$, F. López-Medrano ${ }^{1}$, \\ A. del Palacio², A. Alhambra², \\ E. Álvarez ${ }^{3}, A$. Ramos$^{3}, A$. Pérez $^{4}$, \\ M. Lizasoain 1 , Y. Meije ${ }^{1}$, A. García- Reyne $^{1}$, J. M. Aguado ${ }^{1}$}

1 Infectious Diseases Unit, University Hospital 12 de Octubre, Madrid, Spain

2 Department of Microbiology, University Hospital 12 de Octubre, Madrid, Spain

3 Department of Radiodiagnosis, Division of Neuroradiology, University Hospital 12 de Octubre, Madrid, Spain

4 Department of Neurosurgery, University Hospital 12 de Octubre, Madrid, Spain

\section{References}

1 Robert JY, Raoul JL, Bretagne JF et al. Unusual presentation of a case of brain abscess after endoscopic injection sclerotherapy of esophageal varices. Endoscopy 1991; 23: 237-238

2 Thapar VK, Rajashekharam S, Bapat RD, Kantharia CV. Brain abscess following esophageal dilatation. Dis Esophagus 2003; 16: 145-147

3 Revankar SG. Dematiaceous fungi. Mycoses 2007; 50: 91 - 101

4 Li DM, de Hoog GS. Cerebral phaeohyphomycosis - a cure at what lengths? Lancet Infect Dis 2009; 9: 376-383

5 Meletiadis J, Meis JF, Mouton JW et al. In vitro activities of new and conventional antifungal agents against clinical Scedosporium isolates. Antimicrob Agents Chemother 2002; 46: $62-68$

\section{Bibliography}

DOI $10.1055 / \mathrm{s}-0030-1255804$

Endoscopy 2011; 43: E9-E10

(c) Georg Thieme Verlag KG Stuttgart · New York . ISSN 0013-726X

\section{Corresponding author}

\section{A. Lalueza, MD}

Infectious Diseases Unit

University Hospital 12 de Octubre

Av. Córdoba, km 5,400

Madrid 28041

Spain

Fax: +34-91-3908000

lalueza@hotmail.com 